\title{
Taking training into your own hands
}

\author{
HC Price, J George, EG Wilmot, R Maitland, R Knox, M Atkin and P Choudhary
}

\begin{abstract}
The Young Diabetologists' Forum (YDF) is a group designed and run by specialist trainees in endocrinology and diabetes that aims to provide high quality educational events. The YDF recognised that not all trainees in the specialty had equitable access to training opportunities and resolved to try and remedy the situation. This article describes the history and evolution of the YDF into an organisation representing over 400 trainees in endocrinology and diabetes, providing up to seven training events per year and with a budget of over $£ 200,000$. As well as offering education and training another key purpose of the YDF is to give trainees from around the country the opportunity to meet up and exchange thoughts and ideas. The overall aim of the organisation is to improve the lives of people with diabetes by helping to ensure that future specialists are fully equipped for their role.
\end{abstract}

KEY WORDS: diabetes, medical education, training

\section{Young Diabetologists' Forum}

Traditionally medical education and training has been delivered from the top down and trainees have often been passive participants. However, with the ever increasing complexity of training it is not always possible for local or regional training days or conferences to cover all aspects of the specialty curriculum. Despite there being many educational opportunities available for trainees in diabetes there was no centralised coordinated approach to ensure equitable access to them for all trainees and this led many to question whether their training would be adequate to prepare them for embarking on their consultant career. A variety of options are available to address these concerns. One route is to try and influence the specialist advisory committees who coordinate curriculums and specify training programme requirements. At present the curricula for all specialties are being revised but this may not fully address all concerns. However, a small group of specialist trainees in diabetes and endocrinology decided on a different approach to

HC Price, specialist registrar endocrinology and diabetes, Horton General Hospital, Banbury; J George, MRC career development fellow and specialist registrar endocrinology and diabetes, The Queen's Medical Research Institute, Edinburgh; EG Wilmot, clinical research fellow, Leicester Royal Infirmary; R Maitland, specialist registrar endocrinology and diabetes, University Hospital Lewisham; R Knox, specialist registrar endocrinology and diabetes, Portsmouth Hospitals NHS Trust; M Atkin, specialist registrar endocrinology and diabetes, Portsmouth Hospitals NHS Trust; P Choudhary, lecturer in medicine, King's College London ensure good quality and comprehensive education with equitable access for all.

\section{History}

The Young Diabetologists' Forum (YDF) began life as an annual one-day educational event sponsored by the pharmaceutical industry and held under the auspices of Diabetes UK. It was held on the eve of the Diabetes UK annual professional conference and comprised a series of workshops covering clinical and personal development. The aim of the YDF was to 'represent and support the interests of junior doctors who are involved in any aspect of diabetes care or research' and, in particular, to 'provide education, training and networking opportunities not available elsewhere'.

\section{Evolution}

The YDF gained popularity due to the high quality of its speakers and its education content. Another important aspect was the opportunity for trainees to interact with colleagues from across the country in a social environment. This led the YDF committee, formed from a group of trainees of differing seniorities and regions, to identify further unmet training needs. These included the needs of trainees new to the specialty through to the requirements of those at the end of their training who needed to learn management skills and gain information on the more specialised aspects of diabetes. The YDF approached key UK experts in a variety of areas of diabetes care and put together a portfolio of events that moved from idea to reality over a two-year period.

\section{Educational event portfolio}

\section{Foundation course}

The YDF recognised that many new trainees struggled with the transition from core medical training to specialist training. In response to this it has introduced a foundation course for diabetes, aimed at equipping new trainees with the skills and knowledge required to succeed and inspiring them with their choice of specialty.

\section{Community diabetes course}

The decision to design and run a community course, the first of its kind in the UK, was in direct response to the changes taking place in the specialty that were not adequately reflected in most regional training programmes. The inclusion of a session 
devoted to private providers in diabetes care was a particular highlight and sparked a lively debate.

\section{Insulin pump course}

An insulin pump course, specifically for trainees, run with national experts from the leading UK pump centres is the first of its kind in the UK. Access to training in the management of patients using pumps can be variable because of the concentration of expertise in specialist units. This course will allow those not working in such units to gain valuable knowledge in this area.

\section{Research day}

The YDF has put together a programme to try and expose trainees to opportunities in research and encourage them to participate. This event covers many different aspects of the specialty including basic science, clinical trials and international opportunities. Delegates also hear from UK and world leaders in diabetes research who explain why a period of research should be considered during training.

\section{YDF Scotland}

In order to address issues specifically affecting the devolved nations YDF Scotland was devised and, if successful, will be expanded in order to offer similar events in Northern Ireland and Wales. Feedback indicated that much of the service delivery elements of the courses were specific to England and hopefully this will address this issue.

\section{Diabetes state of the art course}

This course, run in association with the Oxford Centre for Diabetes, Endocrinology and Metabolism, is aimed at trainees ready to apply for consultant posts and includes sessions on interview skills, management and specialist diabetes. It is a prestigious event with much demand for places.

\section{Association for British Clinical Diabetologists and King's Fund diabetes leadership and management courses}

Management forms a large part of the consultant role. The success of the King's Fund diabetes leadership and management courses prompted the YDF to ask it for assistance to develop a bespoke management course for trainees. The course would join key leadership and personal development skills with an understanding of the changing face of diabetes care delivery and how the system works from funding through commissioning to organisation of care delivery.

\section{Support}

Expanding the YDF from an industry run single educational event to a group with a turnover of over $£ 200,000$ has not been easy. It has required vision, leadership and commitment from a core of trainees who have had a desire to give something back to the specialty and their colleagues. Also, it would not have been possible without the amazing support from academic and clinical leaders across the country. No negative responses to a YDF request to speak at an event have been received and the forum has had huge support from national experts who have given up their time to speak to the delegates.

\section{Funding}

Study leave budgets are being squeezed by NHS trusts and the YDF committee has worked very hard to try and ease the problem through sponsorship of its events. Involving multiple industry partners has allowed the forum to be impartial and independent while support from Diabetes UK and the Association for British Clinical Diabetologists $(\mathrm{ABCD})$ has been invaluable

\section{Collaboration and communication}

A key aim of the YDF was to provide opportunities to trainees across the country to come together. A social event at the end of the YDF annual day is a highlight, encouraging networking and dissemination of skills ideas, clinical protocols and research collaborations. The YDF is run by a core committee of seven. Due to the continued success of the forum, however, regional representatives are currently being recruited to support the work of the committee. Members are specialist registrars and specialty trainees drawn from across the country each with different levels of experience. The YDF has managed to achieve a membership of over 400 specialist trainees and new consultants in diabetes and endocrinology. Communication with members happens almost exclusively via the website (www.youngdiabetologists.org) The site includes a wealth of information about diabetes, risk calculators, links to journals and a calendar of events. It receives over one million hits per year. All members also receive a monthly electronic newsletter with news of upcoming courses and events.

\section{Representation}

The YDF provides trainee representation on all the major organisations relevant to the specialty including Diabetes UK, the Society for Endocrinology, the Royal College of Physicians (RCP) Specialty Advisory Committee, the joint societies, $A B C D$ and meetings at the Department of Health.

\section{Improving the lives of people with diabetes}

The YDF operates under the auspices of Diabetes UK which works to improve the lives of people with diabetes. The YDF support this objective by ensuring that those training to be specialists in diabetes care have access to high quality educational events. In order to ensure the quality of the events 
accreditation from the RCP is sought wherever possible. Given that the YDF has access to many doctors working at the front line of managing hospital inpatients with diabetes, members have been able to facilitate other projects including the recent $\mathrm{ABCD}$ audit. ${ }^{1}$ The YDF has also supported the 'Trainees own Perception of Delivery of Care in Diabetes' survey of junior doctors' training needs. ${ }^{2}$ In addition, the forum has been asked by the Society for Endocrinology to develop novel methods of attracting trainees to the specialty. Several places at the YDF annual day will be made available free of charge to individuals interested in a career in diabetes and endocrinology and the forum encourages anyone interested to sign up as a YDF member via the website to learn more.

\section{Going from strength to strength}

The success of the YDF has largely been down to identifying the educational needs of trainees that had previously been unmet. The support, advice, mentoring and networking provided by the organisa- tion have also contributed to its success. Diabetes is the only specialty in which trainees have been able to organise themselves to proactively engage in the delivery of training opportunities to in preparation for the daunting challenge of a consultant career. For further information please see www.youngdiabetologists.org

\section{References}

1 Ahluwalia R, Atkin M, Gallen IW, Winocour PH, Goenka N. Diabetes and endocrinology SpR teaching programmes in the UK: time to set a standard? Diabet Med 2010;27:s125.

2 George JT, Warriner DA, Anthony J et al. Training tomorrow's doctors in diabetes: self-reported confidence levels, practice and perceived training needs of post-graduate trainee doctors in the UK. A multi-centre survey. BMC Med Educ 2008;8:22.

Address for correspondence: Dr HC Price, Horton General Hospital, Oxford Road, Banbury OX16 9AL.

Email: hcprice@doctors.org.uk

\section{RCP BOOKS}

\section{Horizons in Medicine Volume 21}

\section{The proceedings of the Advanced Medicine conference 2009}

Edited by John S Friedland, president of the British Infection Society and chair of the Department of Infectious Diseases and Immunity, Imperial college London

This is the 21st volume in the Horizons in Medicine series, presenting articles in diverse areas of medical knowledge from leaders of their fields.

Based on the 2009 Advanced Medicine conference at the Royal College of Physicians, this volume uniquely blends clinical updates with scientific insight into cutting edge research. A wide range of topics are covered, ranging from those where pathogenetic mechanisms are only beginning to be unravelled, for instance, idiopathic pulmonary fibrosis, to areas where large multi-centre trials have made a great difference to practice, such as the management of transient ischaemic attacks.

This unique publication presents essential facts and information on the latest medical developments to a wide range of readers such as the consultant physician, general practitioner or doctor in training, and also those from developing countries.

For detailed contents and a list of authors please visit http://bookshop.rcplondon.ac.uk/details.aspx?e=293

\section{Published November 2009 ISBN 978-1-86016-368-5}

\section{Special offer to fellows and members $£ 22.00$}

(Please supply your RCP number with the order to receive the special price)

Standard price $£ 32.00$ UK and overseas

(all prices include postage and packing)

Please quote the reference Clinical Medicine when making your order

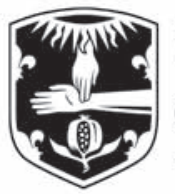

